\title{
Diffusion-weighted imaging in the evaluation of perianal fistula and abscess
}

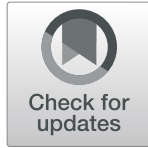

\author{
Laila Adel Mohsen * (10) and Nasr Mohamed Osman
}

\begin{abstract}
Background: Perianal fistulas are a common inflammatory condition of the anal canal and perianal tissue. The introduction of MRI in the evaluation of suspected perianal inflammation has greatly improved the surgical outcome of these patients as it allowed the direct visualization of anal sphincters, levator ani muscle, and the extent of the disease in relation to these vital structures. Diffusion-weighted imaging (DWI) has been under extensive research to evaluate whether it adds any value in the setting of perianal inflammation.

The aim of our study was to evaluate the visibility of perianal inflammation on DWI and evaluate the diffusion characteristics of perianal fistulas and abscesses and how accurately can DWI classify perianal disease.

Results: Mean age of patients was $37 \pm 8.9$ years old. The study included 30 fistulas and 15 abscesses. Seven patients had more than 1 fistula or fistula and abscess. Perianal abscesses were well visualized equally on DWI and T2W images and correctly classified by DWI, when compared to post-contrast images. Perianal fistulas without abscesses, on the other hand, had variable visibility scores. Although the visibility of these fistulas on DWI was generally less than T2W and combined DWI and T2W, yet this did not reach a significant level and it was not significantly different between positive and negative inflammatory groups. Combined DWI and T2W evaluation had the highest performance and accurately classified $97.8 \%$ of perianal fistulas and abscesses, and only 1 case was misclassified (2.3\%).

Conclusion: DWI had a good performance in the evaluation of perianal inflammatory disease. However, combined DWI and T2W evaluation had better performance which was not significantly different from combined T2W and post-contrast images.
\end{abstract}

Keywords: Anal fistula, Perianal glands, Diffusion-weighted MRI, Diffusion MRI

\section{Background}

Perianal fistulas represent a common inflammatory condition of the anal canal and perianal tissues. Most of these fistulas occur due to idiopathic inflammation of the cryptogenic glands in the anal mucosa. Less common causes include Crohn's disease, child birth-related trauma, or radiotherapy. The advent of MRI has offered a major help to these patients as it allowed the direct visualization of the fistulous tract, its site in relation to the anal sphincters, and the extent of the fistula-and its abscess-in relation to the anal sphincters and levator

*Correspondence: dr.laila.adel77@gmail.com

Radiology Department, Minia University, Minia, Egypt ani muscle. This has further improved the surgical outcome for these patients.

Diffusion-weighted imaging (DWI) has been studied by several researchers to evaluate whether it adds any value to other MRI sequences in the evaluation of perianal inflammation. Some authors have suggested that DWI is more sensitive than T2W sequence regarding the visibility of the fistula [1]. Others suggested that restricted diffusion indicated activity of the fistula, and some even suggested that it represents a good alternative for post-contrast imaging in case gadolinium cannot be used $[2,3]$. However, these studies are still few, and the applicability of DWI in the imaging of perianal fistulas is still questionable.

\section{Springer Open}

() The Author(s). 2020 Open Access This article is licensed under a Creative Commons Attribution 4.0 International License, which permits use, sharing, adaptation, distribution and reproduction in any medium or format, as long as you give appropriate credit to the original author(s) and the source, provide a link to the Creative Commons licence, and indicate if changes were made. The images or other third party material in this article are included in the article's Creative Commons licence, unless indicated otherwise in a credit line to the material. If material is not included in the article's Creative Commons licence and your intended use is not permitted by statutory regulation or exceeds the permitted use, you will need to obtain permission directly from the copyright holder. To view a copy of this licence, visit http://creativecommons.org/licenses/by/4.0/. 
Aim of the study: to compare the visibility of perianal fistulas and abscesses using T2W, DWI, and combined DWI and T2W. The St. James's University Hospital classification of perianal fistulas based on DWI and combined DWI and T2W evaluation was also compared to this classification based on combined T2W and postcontrast T1W images.

\section{Methods}

\section{Patients' selection}

This prospective study included 38 patients with a total of 45 cryptogenic perianal fistulas and abscesses. These patients presented to the surgery clinic during the time period from August 2018 to August 2019. These patients were then referred for MRI evaluation if a perianal fistula is suspected. Inclusion criteria: Any patient with suspected perianal fistula or abscess, eGFR $\geq 60 \mathrm{ml} / \mathrm{min} /$ $1.73 \mathrm{~m}^{2}$, and no contra-indication to IV gadolinium contrast or to MRI. Exclusion criteria: Patients with other types or perianal fistulas, any contra-indication to gadolinium contrast or MRI, e.g., claustrophobia. Patients with perianal abscesses who refused surgery-despite being indicated-were also excluded from the study to avoid causing bias to the ADC analysis.

The decision of surgery was based solely on clinical and laboratory evaluation, which included the following criteria: severe pain or restriction of daily activity, restriction of sexual activity, reddish edematous skin, pus discharge, and increased serum C-reactive protein (CRP) levels ( $>5$ $\mathrm{mg} / \mathrm{L}$ ). Fistulas which were confirmed to show pus at surgery were considered to be active, whereas fistulas which did not reveal pus, did not require surgery, or were associated with normal CRP levels were considered non-active. Patients were classified according to the activity of fistulas into Positive Inflammatory Activity (PIA) and Negative Inflammatory Activity (NIA) groups [2, 4].

\section{MR imaging}

All patients were imaged on a 1.5-T Philips Achieva machine (Philips Healthcare, Best, the Netherlands). The body coil (dStream Torso coil) was used. Imaging sequences included T1W, T2W, fat suppressed T1W and T2W, STIR as well as post-contrast T1W sequences in 3 orthogonal planes. The axial plane was used for evaluation. DWI was added to the study with the following criteria: axial, TR/TE $=6400 / 100 \mathrm{~ms}$; slice thickness $=5$ $\mathrm{mm}$; interslice gap $=0.5 \mathrm{~mm}$; number of slices $=24$; matrix size $=188 \times 192$, with reconstruction to $256 \times$ 256; FOV $=385 \mathrm{~mm} \times 385 \mathrm{~mm} ; \mathrm{NEX}=4$; and $b$ values of 100,300 , and $600 \mathrm{~s} / \mathrm{mm}^{2}$. For the T2W sequence, the acquisition parameters were as follows: axial, TR/TE = $3840 / 90 \mathrm{~ms}$; slice thickness $=5 \mathrm{~mm}$; interslice gap $=0.6$ $\mathrm{mm}$; matrix size $=320 \times 220$; and FOV $=380 \times 240$ $\mathrm{mm}$. For post-contrast fat suppressed T1W-SPIR, the acquisition parameters were as follows: Axial, TR/TE $=$ $570 / 8 \mathrm{~ms}$; slice thickness $=5 \mathrm{~mm}$; interslice gap $=0.6$ $\mathrm{mm}$; matrix size $=320 \times 220 ; \mathrm{FOV}=380 \times 385 \mathrm{~mm}$.

\section{Image analysis}

The perianal fistula was evaluated on T2W, DWI and post-contrast fat-suppressed T1W sequences as per its visualization and extent. Both authors (LM, 16 years of experience: NO, 26 years of experience) evaluated all patients in consensus. T2W and DWI images were evaluated separately 2 weeks apart; then, both sequences were simultaneously evaluated after 2 more weeks, to avoid recall bias. Only the DWI images with $b$ value of $600 \mathrm{~s} /$ $\mathrm{mm}^{2}$ were used for visibility comparison. The visibility of fistulas was graded on a 3-point scale from 0 to 2 , as follows: $0=$ no evident fistula, $1=$ probably fistula, and 2 = distinct fistula. Scores of 1 and 2 were indicative of fistula presence (Fig. 1) [4]. ADC values were recorded from the corresponding ADC maps. A small ROI was placed within the area of abnormality-on the slice where it is best visualized-and the minimum ADC value was recorded.

To evaluate the performance of DWI in grading the perianal inflammation, the extent of the perianal fistula/ abscess was determined on DWI, combined T2W and DWI and combined T2W and post-contrast images, separately [5]. The fistula was then graded according to St. James's University Hospital classification using each of the DWI, combined T2W and DWI, and combined T2W and post-contrast images, separately [6]. The combined T2W and post-contrast images were used as the reference for grading the perianal fistula/abscess [7]. In cases of perianal abscess with non-visualization of the related fistula, the same steps were followed; minimum $\mathrm{ADC}$ value was recorded from the abscess core, and the grade was determined using DWI, combined T2W and DWI, and combined T2W and post-contrast images.

\section{Statistical analysis}

Statistical analyses were performed using SPSS software (version 21.0; SPSS Inc., Chicago, IL, USA). Numerical data, e.g., age and ADC value, is represented as mean \pm standard deviation, while non-parametric data is represented as percentage. The visibility scores on each of the DWI and the T2W images were compared to those on the combined T2W and DWI image evaluation using chi-square test. The same visibility scores (DWI images alone, T2W images alone, and combined T2W and DWI image evaluation) were compared between PIA and NIA groups, also using chi-square test. All perianal abscesses belonged to the PIA group and were well visualized on both sequences, so they were excluded from the 2 later analyses. Independent sample $T$ test was used to compare between $A D C$ values of perianal fistulas between 

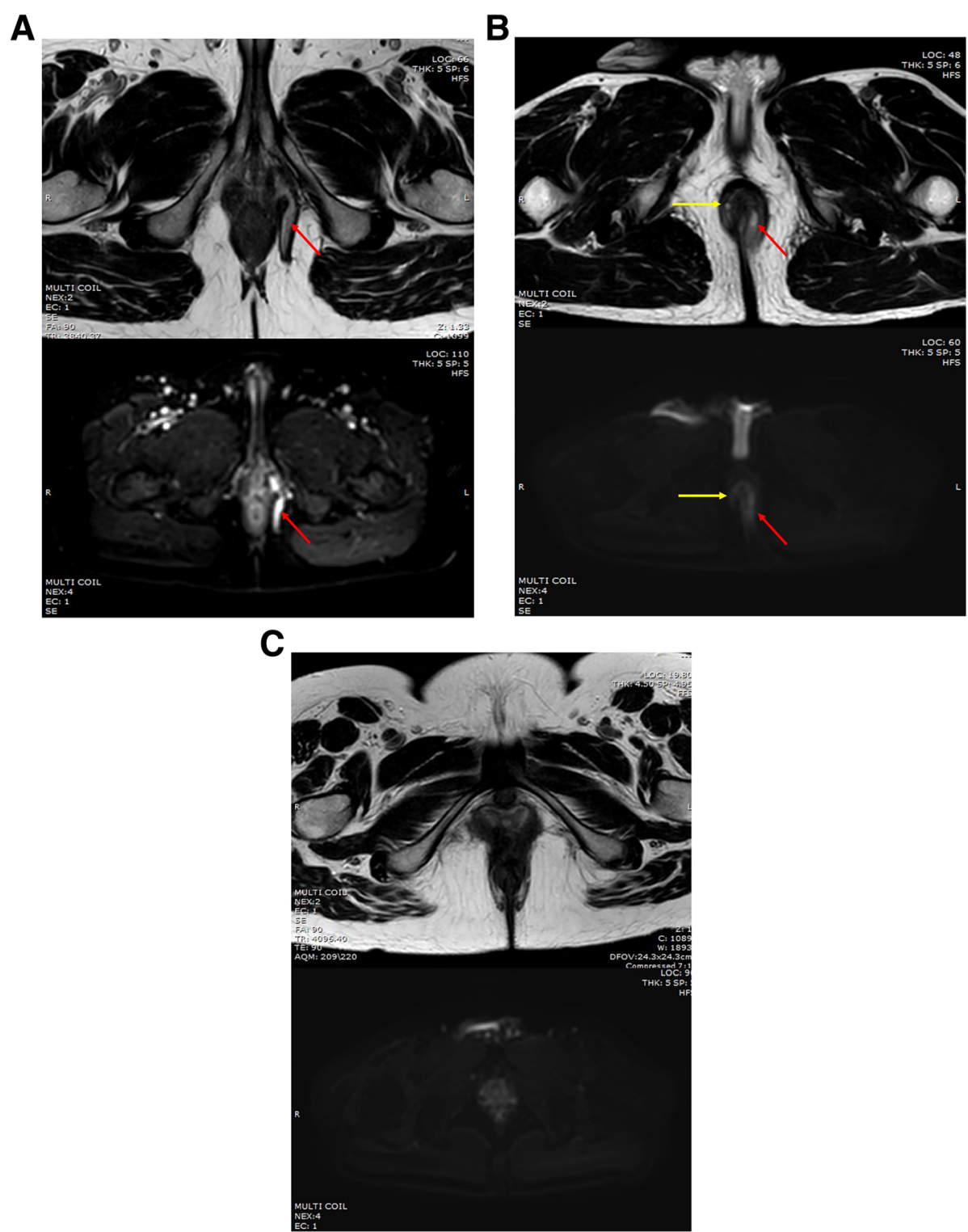

Fig. 1 Exemplary images for the image evaluation in each of T2W and DWI images. a Score 2 in both T2W and DWI as the fistula is well visualized in both images. b Score 2 in T2W and score 1 in DWI, as the fistula was well visualized in T2W and suboptimally visualized in DWI (yellow arrows). Another fistula was scored 2 in both images (red arrow). C) Score 0 in both T2W and DWI as no fistula could be seen in either images. This T2W image (C) is only a representative image from another patient, without perianal fistula

PIA and NIA groups. Perianal abscesses were also excluded from this analysis because they all belonged to the PIA group. ADC values were correlated to the CRP level and leucocytic count using Pearson's bivariate correlation test. Finally, the grading of the perianal fistula/abscess (St. James's University Hospital grading system) on DWI and combined DWI and T2W was compared to the combined T2W and postcontrast evaluation and between PIA and NIA groups using Wilcoxon signed rank test. Significance level is considered if $p<0.05$.

\section{Results}

\section{Demographic analysis}

The study included 38 patients, 35 were males and 3 were females. Mean age was $37 \pm 8.9$ years old with a range of 24-60 years of age.

The total number of cryptogenic perianal fistulas and abscess was 45 . These included 30 fistulas and 15 abscesses. Seven patients had more than 1 fistula or fistula and abscess. The sites of these fistulas/abscesses were inter-sphincteric $(n=25,55.6 \%)$, trans-sphincteric $(n=$ $11,24.4 \%)$, and extra-sphincteric $(n=9,20 \%)$. 
Table 1 Demographic features of PIA and NIA groups

\begin{tabular}{llll}
\hline & PIA & NIA & $\begin{array}{l}\text { Significance } \\
\text { level }\end{array}$ \\
\hline Age & $38.4 \pm$ 10 years & $35 \pm$ 6.6 years & 0.2 \\
Gender & 17 males, 1 female & 18 males, 2 females & 0.55 \\
St. James's & Grade 1: 6 & Grade 1: 15 & 0.015 \\
University & Grade 2: 4 & Grade 2: 0 & \\
Hospital grade & Grade 3: 1 & Grade 3: 3 & \\
& Grade 4: 5 & Grade 4: 0 & \\
& Grade 5: 4 & Grade 5: 2 & \\
& Extra-sphincteric: 2 & Extra-sphincteric: 3 & \\
& & &
\end{tabular}

According to St. James's University Hospital classification, there were 21 grade 1 fistulas, 4 grade 2 abscesses, 4 grade 3 fistulas, 5 grade 4 abscesses, and 6 grade 5 fistulas and abscesses. Five extra-sphincteric fistulas/abscesses were recorded. Extra-sphincteric fistulas that reached to the level of the levator ani muscle were considered grade 5 fistulas $(n=4)$ (Table 1$)$.

\section{DWI and T2 visibility of perianal fistulas}

In perianal fistulas $(n=30), 15$ fistulas $(50 \%)$ were well visualized (score 2) on DWI, in comparison to 20 fistulas (66.7\%) well visualized on T2W. Fifteen fistulas were either not visualized (score $0, n=5$ ) or poorly visualized (score 1 , $n=10$ ) on DWI. In comparison, 9 fistulas were poorly visualized (score 1) on T2W and only 1 was not visualized (score 0 ). The visibility scores on $\mathrm{T} 2 \mathrm{~W}$ were not significantly different from that of DWI $(p=0.14)$ and both of them were less than the visibility scores of the combined DWI and T2W evaluation, although not significant. This is shown in Table 2. All perianal abscesses were well visualized on both sequences, with the same size, location, and extension.

The visibility scores of perianal fistulas on DWI were not significantly different between PIA and NIA groups $(p=0.78)$. Similarly, these scores on T2W did not show any significant variation between PIA and NIA groups $(p=0.49)$. This is shown in Table 3 .

\section{$A D C$ values and activity}

The ADC values for perianal fistulas was $1.39 \pm 0.4 \times 10^{-3}$ $\mathrm{mm}^{2} / \mathrm{s}$, while for abscesses, it was $0.8 \pm 0.66 \times 100^{-3} \mathrm{~mm}^{2} / \mathrm{s}$,

Table 2 Visibility scores for perianal fistulas between T2W, DWI, and combined T2W and DWI

\begin{tabular}{lllll}
\hline $\begin{array}{l}\text { Visibility score for } \\
\text { perianal fistulas }\end{array}$ & T2W & DWl & $\begin{array}{l}\text { Combined T2W } \\
\text { and DWl }\end{array}$ & Significance level \\
\hline Score 2 & 20 & 15 & 29 & $0.08-0.26$ \\
Score 1 & 9 & 10 & 1 & \\
Score 0 & 1 & 5 & 0 & \\
\hline
\end{tabular}

Table 3 Visibility scores for each sequence between PIA and NIA groups

\begin{tabular}{lllll}
\hline & & PIA $(n=7)$ & NIA $(n=23)$ & $p$ value \\
\hline DWI visibility scores & Score 2 & 3 & 12 & 0.74 \\
& Score 1 & 3 & 7 & \\
& Score 0 & 1 & 4 & \\
T2W visibility scores & Score 2 & 6 & 14 & 0.53 \\
& Score 1 & 1 & 8 & \\
& Score 0 & 0 & 1 & \\
Combined DWI and T2W & Score 2 & 7 & 22 & 0.75 \\
visibility scores & & & & \\
\hline
\end{tabular}

with significant difference between both entities $(p=0.001)$. This is displayed in Fig. 2.

There was no significant difference between PIA and NIA groups regarding the ADC value of perianal fistulas (PIA $1.3 \pm 0.5 \times 10^{-3} \mathrm{~mm}^{2} / \mathrm{s}$ and NIA $1.43 \pm 0.4 \times 10^{-3}$ $\left.\mathrm{mm}^{2} / \mathrm{s}, p=0.45\right)$. This is displayed in Fig. 3. ADC values did not reveal any significant correlation to the CRP level $(p=0.38)$ or leucocytic counts $(p=0.59)$.

\section{Grading of perianal fistulas}

Using the St. James's University Hospital classification, 38 fistulas and abscesses were correctly classified by DWI alone $(84.4 \%)$, whereas 6 cases $(13.3 \%)$ could not be classified due to poor or non-visualization and 1 case $(2.2 \%)$ was misclassified. Two of these cases belonged to the PIA group (28.6\% of the PIA group and $4.4 \%$ of the entire sample) and 5 cases belonged to the NIA group. The DWIbased grading was significantly less than the combined $\mathrm{T} 2 \mathrm{~W}$ and post-contrast images in the classification of perianal fistulas and abscesses $(p=0.023)$ when testing the entire sample. However, for the PIA group only, DWI was not significantly different from combined T2W and post-contrast images $(p=0.66)$.

On the other hand, 44 perianal fistulas and abscesses were correctly classified using combined T2W and DWI evaluation (97.8\%). The only case, which could not be well visualized on both sequences, belonged to the NIA group. The grading of perianal fistula/abscess using combined T2W and DWI evaluation was not significantly different from that using combined T2W and post-contrast images when testing the entire sample $(p=0.32)$ or when testing the PIA group separately $(p=1)$ (Figs. 4,5 , and 6 ).

\section{Discussion}

MR imaging of suspected perianal inflammatory pathologies is an established method for diagnosis and defining the extent of this inflammation. The standard MRI sequences used for those patients include basic anatomical sequences with pre- and post-contrast images. The principle role of MRI in the setting of perianal fistulas is to define the extension of the tract, side branches, and 


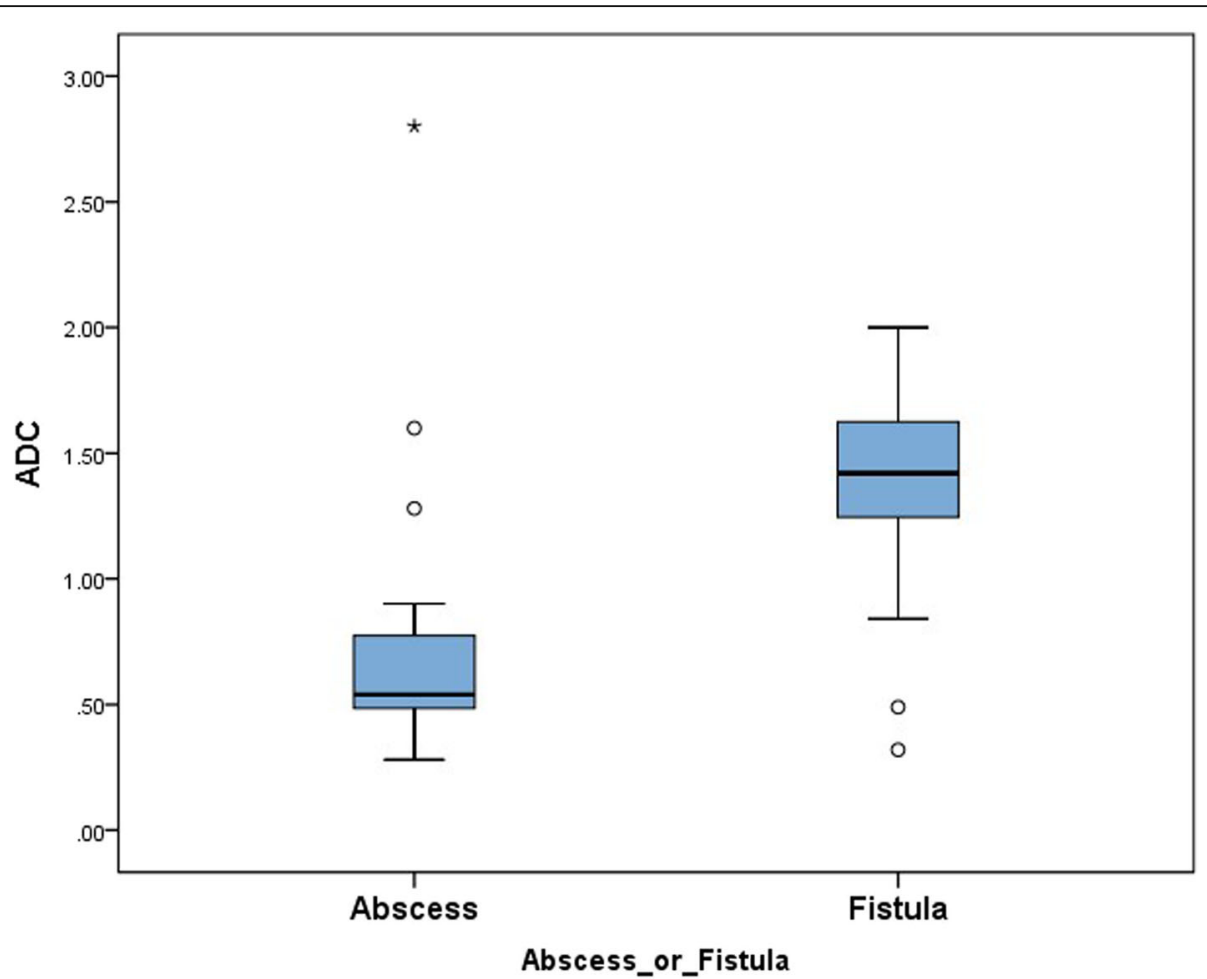

Fig. 2 Boxplot for the ADC values between perianal fistulas and abscesses revealing significant difference between them

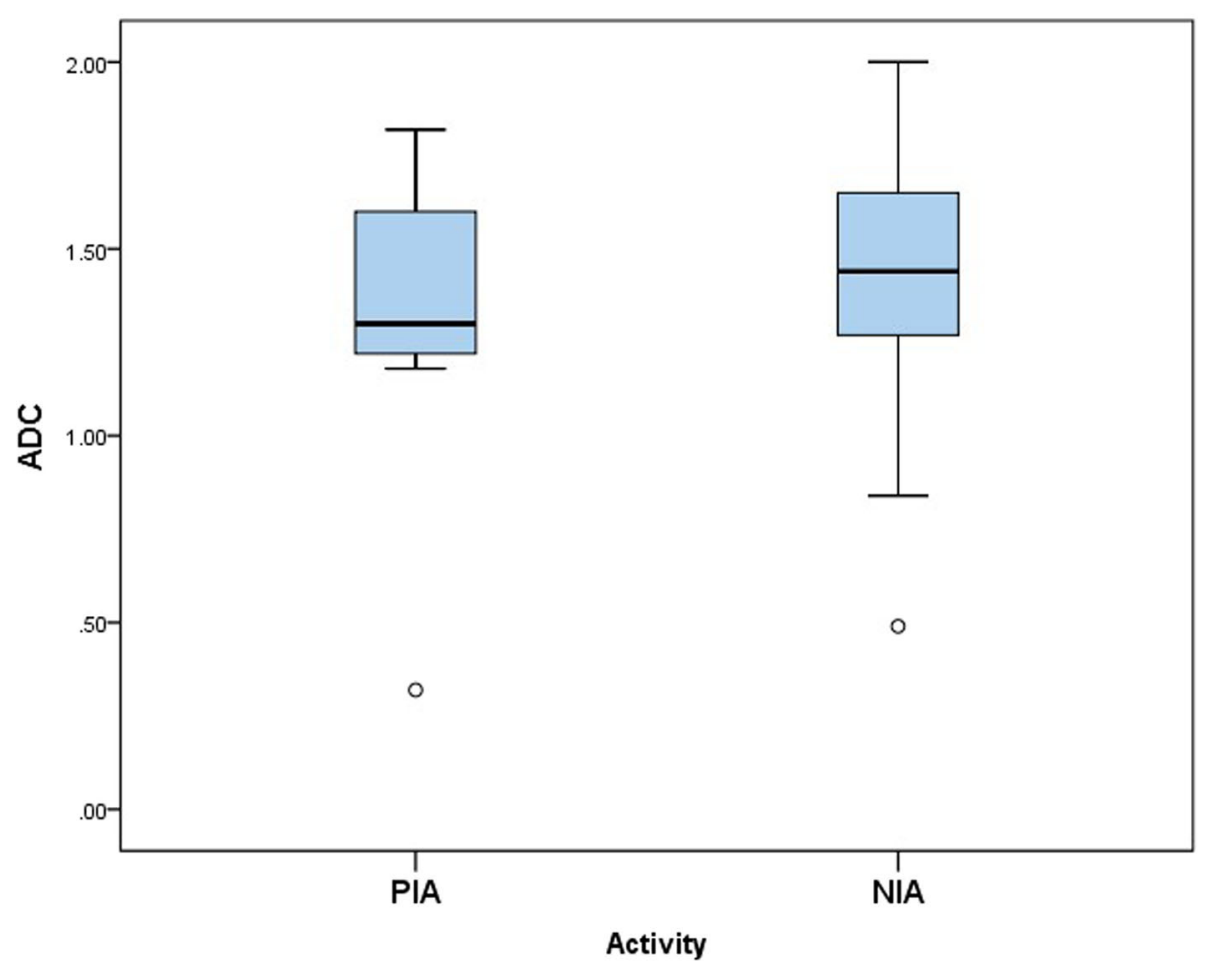

Fig. 3 Boxplot for the ADC values of perianal fistulas between PIA and NIA groups revealing no significant difference between them 

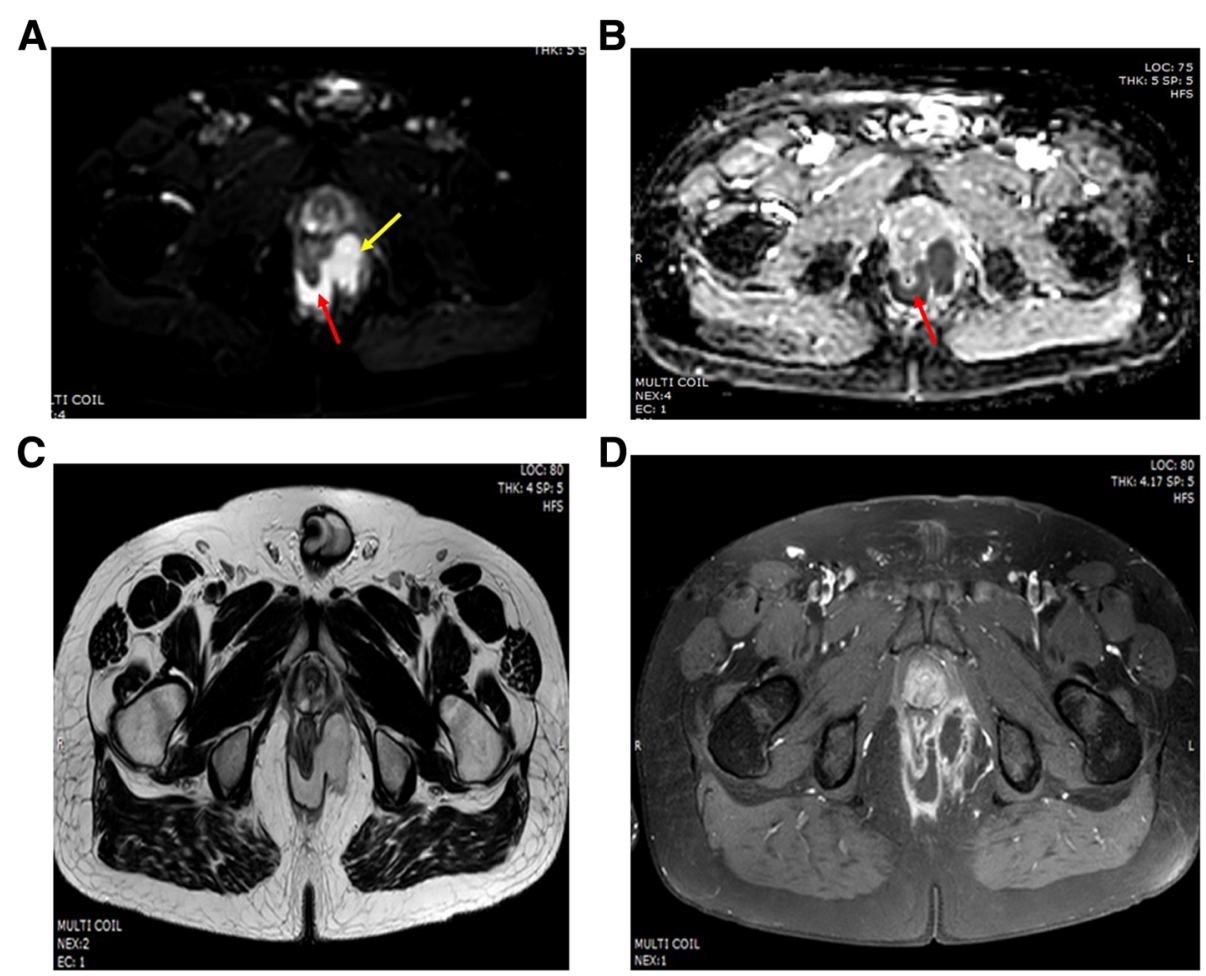

Fig. 4 Extra-sphincteric perianal abscess grade 4. a DWI trace image showing an inter-sphincteric abscess (red arrow) that extends through the external sphincter at 2 o'clock to form a collection in the left anal fossa (yellow arrow). $\mathbf{b}$ ADC map revealing the markedly low ADC value of the abscess core (red arrow). c T2W and $\mathbf{d}$ post-contrast T1W-SPIR images confirming the same extent of the abscess
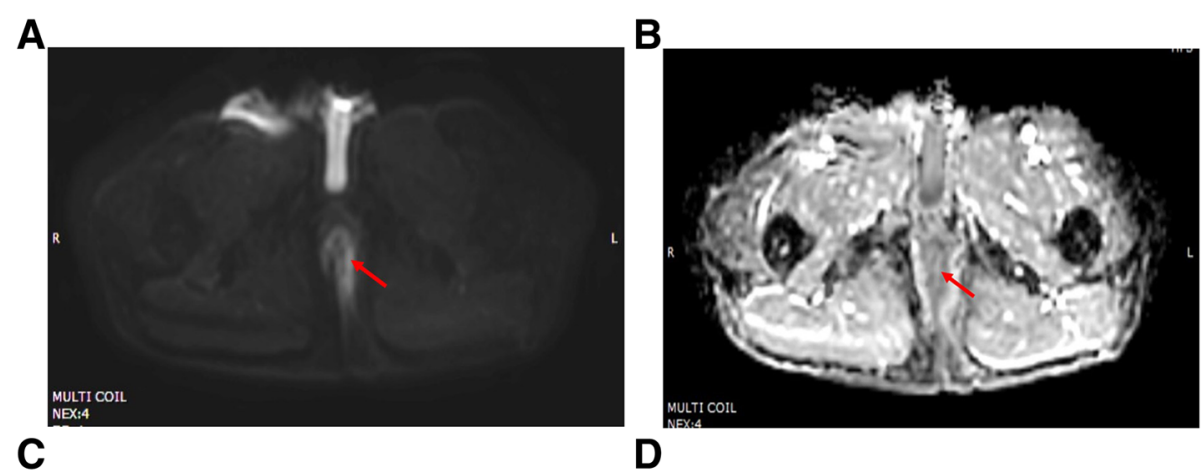

D
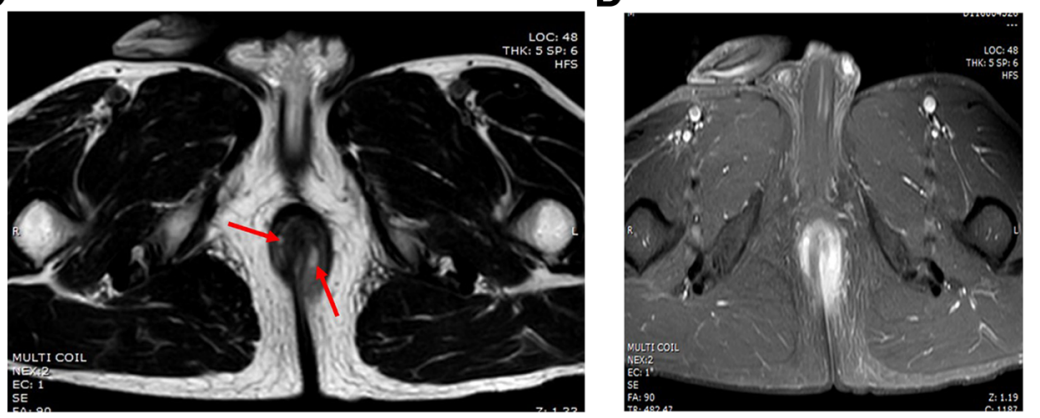

Fig. 5 Inter-sphincteric perianal fistulas grade 1. Two fistulas are seen at 3 o'clock and 10 o'clock (red arrows). a DWI trace image clearly showing the left sided fistula and poorly showing the right sided fistula. b ADC map revealing increased ADC value of both fistulas. c T2W image clearly showing both fistulas and absence of any abscesses. $\mathbf{d}$ Post-contrast T1W-SPIR confirms the findings of combined T2W and DWI 
A

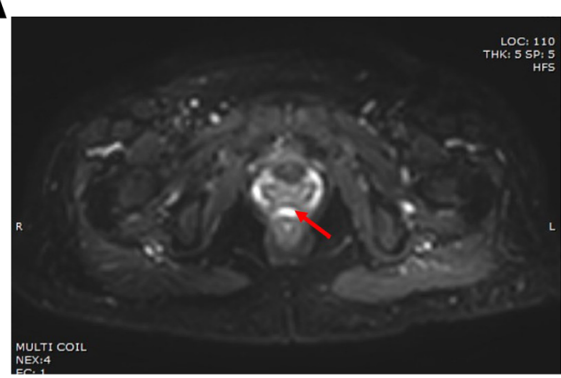

C

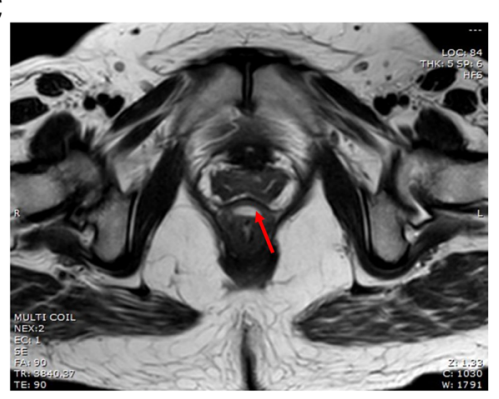

B
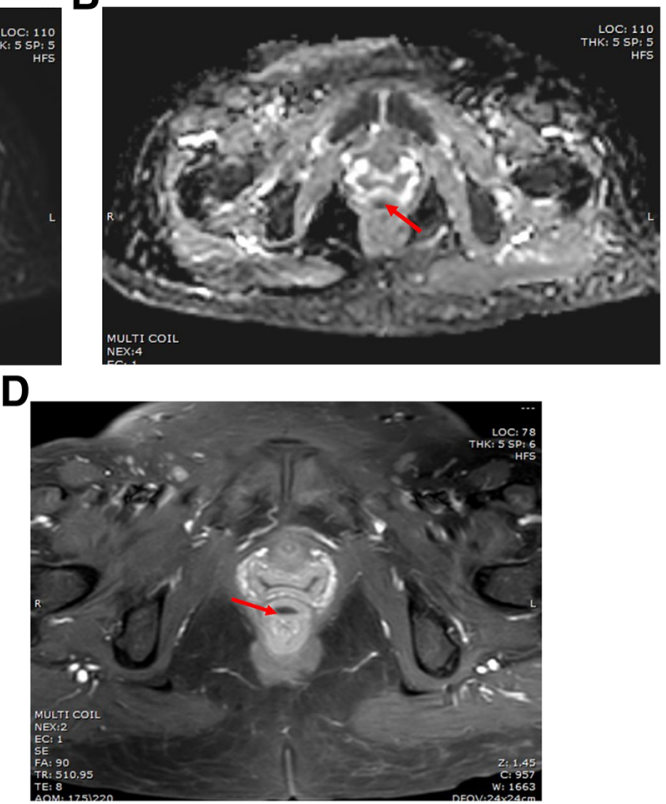

Fig. 6 The only case misclassified by DWI. a DWI trace image showing an inter-sphincteric fistula at 12 o'clock. b ADC map revealing a tiny lumen for the fistula with low ADC value $\left(0.9 \times 10^{-3} \mathrm{~mm}^{2} / \mathrm{s}\right)$. c T2W image revealing similar findings as DWI. $\mathbf{d}$ Post-contrast T1W revealing this was a small abscess. This patient had low CRP and did not have any surgery (NIA group)

whether there are any deep abscesses, especially at supra-levator level. Post-contrast sequences are an essential component of this study to better reveal hidden extension, branching tracts, and suspected abscesses. Active granulation tissue in the edges of the fistula enhances diffusely, while its lumen does not. Inflammation that surrounds the fistulous tract also enhances diffusely $[8,9]$. An abscess gives the characteristic ring enhancement which confirms its diagnosis and outlines its extent. Few authors tried to correlate the enhancement of the fistula to its activity [8-14]. One author suggested that rapid and maximum enhancement during dynamic MRI scanning correlated well to the disease activity. However, the applicability of this dynamic imaging is limited by the poor spatial coverage (to improve the temporal resolution) which limits the evaluation of the extent of inflammation [15].

DWI is recently being studied by some researchers to compare its performance in visualizing and grading perianal fistulas and abscesses. Extra-cranially, oncologic applications of DWI are the most common. However, the evaluation of abscesses is a very important application for DWI, owing to the maximum contrast between the abscess cavity and the surrounding inflammation on the DWI image [1-4, 16-19].

Some authors suggested that DWI was more sensitive than T2W sequence in the visibility of perianal fistulas. Dohan suggested that DWI had a sensitivity of $100 \%$ in detecting perianal fistulas, whereas T2W had a sensitivity of $91.2 \%$ [1]. Other authors suggested that the visibility of perianal fistulas was significantly higher with combined DWI and T2W than with T2W alone [3, 4, 7]. In our study, we were unable to reproduce the former results. In our sample of patients, DWI was equally effective as T2W sequence in visualizing perianal fistulas and abscesses $(p=$ $0.14)$, although DWI has detected less number of fistulas than T2W in all visibility grades. But we did agree with Cavusoglu et al., Hori et al., and Bakan et al. that the visibility of perianal fistulas was higher using combined DWI and T2W evaluation, where we detected $96.7 \%$ of perianal fistulas $[3,4,7]$. Only 1 fistula could not be visualized on both DWI and T2W; this was visualized on post-contrast images, and this patient had a grade 1 perianal fistula with normal CRP; the patient was in the NIA group and did not require surgery. Visibility of perianal fistulas on DWI images was not significantly different for PIA and NIA groups. Perianal abscesses, on the other hand, were equally well visualized on both sequences.

Perianal fistulas generally had higher ADC values than perianal abscesses. The average ADC value for perianal fistulas was $1.39 \pm 0.4 \times 10^{-3} \mathrm{~mm}^{2} / \mathrm{s}$. For perianal abscesses, the average ADC value was $0.8 \pm 0.66 \times 10^{-3}$ $\mathrm{mm}^{2} / \mathrm{s}$. This comes in agreement with other authors, reflecting the viscid nature of the abscess core, which is not seen in fistulous tracts $[1,2]$.

The ADC of perianal fistulas did not show any correlation to the disease activity as determined by CRP and leucocytic count ( $p=0.38$ and $p=0.59$, respectively). It 
also did not vary between PIA and NIA groups $(p=0.45)$. This came in contradiction to some authors who suggested that ADC values were lower in PIA patients [2]. The reason for the contradiction between our results and Yoshizako et al. may be related to the method of ADC measurement, where in their study, they used a free ROI that encompassed the entire lesion and calculated the mean $\mathrm{ADC}$ value, whereas in our study, we used a small ROI within the center of the lesion and calculated the minimum ADC value [2]. It was also postulated by some authors that small abscesses or pus collection may give an artifactual high ADC value than large abscesses which is probably related to the difficult positioning of the ROI in small abscesses [20]. This was noted in one of our patients, where she had a small abscess with ADC value of $0.9 \times 10^{-3} \mathrm{~mm}^{2} / \mathrm{s}$. Another explanation for the overlap of ADC values of PIA and NIA groups may be related to the different concentrations of inflammatory cells in small and large abscesses, different immune response of the patient, and age of the abscess; all of these factors influence the viscosity of the pus and accordingly alter the ADC value $[2,20,21]$. Some authors suggested that there was a significant difference between ADC values of PIA and NIA groups in cases of fistulas associated with abscess, but not for fistulas without abscesses. However, in their study, the authors used a large ROI that encompassed a large area of the lesion, so the viscid nature of the abscess probably dominated the ADC measurement, rather than the fistula itself [4]. In our study, all perianal abscesses belonged to the PIA group and the ADC of abscesses were significantly lower than that of perianal fistulas without abscesses, which comes in agreement with Bakan et al. [4].

Using the St. James's University Hospital classification, DWI accurately classified $84.4 \%$ of the perianal fistulas and abscesses. Only 1 case $(2.2 \%)$ was misclassified by DWI alone; this patient had a very small collection with high ADC value, so it was considered grade 1 on DWI images, while on post-contrast images, it was considered grade 2 . DWI alone was significantly less than postcontrast images in the accurate classification of perianal disease, mainly in the NIA group, but not in the PIA group, who are more likely to have surgeries. Using combined DWI and T2W evaluation, $97.8 \%$ of the perianal fistulas and abscesses were accurately classified and this was not significantly different between PIA and NIA groups. Our results agree with the results of Cavusoglu et al., where he states that the combined DWI and T2W evaluation had a high diagnostic performance that is not significantly different from the combined T2W and post-contrast images evaluation [7].

\section{Conclusion}

In our study, we concluded that DWI alone was not superior to $\mathrm{T} 2 \mathrm{~W}$ regarding the visibility of perianal fistulas and abscesses. Although T2W evaluation detected higher number of fistulas, yet this did not reach significant levels, when compared to DWI. The best performance was for combined DWI and T2W evaluation, although it was not significantly higher than either sequence alone. We believe that DWI is better used as part of the entire MRI study, i.e., it should not replace T2W sequence.

We were able to confirm that DWI may be used as an alternative for post-contrast images, especially in patients with perianal abscesses. DWI could accurately determine the extent of the abscess. On the other hand, in patients with perianal fistulas without abscesses, we believe that DWI could not be reliably used to replace post-contrast sequences. In contrast, it may be used with other basic sequences, to enhance visibility of poorly visible fistulas. Using DWI and T2W sequences, $97.8 \%$ were accurately seen and classified. And this applies to both inflammatory activity groups. Although, in our study, only 1 case was misclassified ( $2.2 \%$ of cases), yet, this case belonged to the NIA group of patients, who are unlikely to have surgeries, and thus no change of their proposed management. We do still need a larger scale study to confirm the percentage of error when using combined DWI and T2W evaluation to classify perianal abscess and fistulas.

\section{Limitations}

The first limitation, in our study, is the low number of cases. The second limitation is that some patients with perianal fistulas refused surgery, despite being indicated. This may have affected their classification into PIA and NIA groups and accordingly may have altered the results. We tried to reduce this bias by excluding patients with pre-operative diagnosis of perianal abscesses, who refused the surgery. Finally, our results may vary from other authors, who used higher $b$ values for the DWI sequence $\left(1000 \mathrm{~s} / \mathrm{mm}^{2}\right)$ or used a large ROI for the recording the $\mathrm{ADC}$ value.

\section{Abbreviations \\ ADC: Apparent diffusion coefficient; DWl: Diffusion-weighted imaging; NIA: Negative inflammatory activity; PIA: Positive inflammatory activity}

\section{Acknowledgements}

Not applicable.

\section{Authors' contributions}

LM: Image analysis, Statistical analysis and writing the manuscript. NO: Data collection, Image analysis and revision of the manuscript. All authors have read and approved the manuscript.

\section{Funding}

No funding is provided for this work.

Availability of data and materials

The datasets used and/or analyzed during the current study are available from the corresponding author on reasonable request. 


\section{Ethics approval and consent to participate}

The study was approved by the Faculty of Medicine Research Ethics Committee (FMREC), Minia University, Approval No. 205:7/2019. All patients included in this research gave written informed consent to participate in this study. None of the patients included in this study was less than 16 years old, deceased, or unconscious when the study consent was requested; accordingly, a written informed consent by a legal guardian was not needed.

\section{Consent for publication}

All patients included in this research gave written informed consent to publish the data contained in this study.

\section{Competing interests}

The authors declare no competing interests.

Received: 11 December 2019 Accepted: 23 April 2020

Published online: 04 May 2020

\section{References}

1. Dohan A, Eveno C, Oprea R, Pautrat K, Placé V, Pocard M, Hoeffel C, Boudiaf M, Soyer P (2014) Diffusion-weighted MR imaging for the diagnosis of abscess complicating fistula-in-ano: preliminary experience. Eur Radiol 24(11):2906-2915

2. Yoshizako T, Wada A, Takahara T, Kwee TC, Nakamura M, Uchida K, Hara S, Luijten PR, Kitagaki H (2012) Diffusion-weighted MRI for evaluating perianal fistula activity: feasibility study. Eur J Radiol 81(9):2049-2053

3. Hori M, Oto A, Orrin S, Suzuki K, Baron RL (2009) Diffusion-weighted MRI: a new tool for the diagnosis of fistula in ano. J Magn Reson Imaging 30(5): 1021-1026

4. Bakan S, Olgun DC, Kandemirli SG, Tutar O, Samanci C, Dikici S, Simsek O, Rafiee B, Adaletli I, Mihmanli I (2015) Perianal fistula with and without abscess: assessment of fistula activity using diffusion-weighted magnetic resonance imaging. Iran J Radiol 12(4):e29084

5. Parks AG, Gordon PH, Hardcastle JD (1976) A classification of fistula-in-ano. Br J Surg 63(1):1-12

6. Morris J, Spencer JA, Ambrose NS (2000) MR imaging classification of perianal fistulas and its implications for patient management. Radiographics. 20(3):623-635

7. Cavusoglu M, Duran S, Sözmen Cilız D, Tufan G, Hatipoglu Çetin HG, Ozsoy A, Sakman B (2017) Added value of diffusion-weighted magnetic resonance imaging for the diagnosis of perianal fistula. Diagn Interv Imaging 98(5): 401-408

8. Halligan S, Stoker J (2006) Imaging of fistula in ano. Radiology. 239(1):18-33

9. Szurowska E, Wypych J, Izycka-Swieszewska E (2007) Perianal fistulas in Crohn's disease: MRI diagnosis and surgical planning: MRI in fistulazing perianal Crohn's disease. Abdom Imaging 32(6):705-718

10. Bell SJ, Halligan S, Windsor AC, Williams AB, Wiesel P, Kamm MA (2003) Response of fistulating Crohn's disease to infliximab treatment assessed by magnetic resonance imaging. Aliment Pharmacol Ther 17(3):387-393

11. Schwartz DA, Wiersema MJ, Dudiak KM, Fletcher JG, Clain JE, Tremaine WJ, Zinsmeister AR, Norton ID, Boardman LA, Devine RM, Wolff BG, YoungFadok TM, Diehl NN, Pemberton JH, Sandborn WJ (2001) A comparison of endoscopic ultrasound, magnetic resonance imaging, and exam under anesthesia for evaluation of Crohn's perianal fistulas. Gastroenterology. 121(5):1064-1072

12. Buchanan G, Halligan S, Williams A, Cohen CR, Tarroni D, Phillips RK, Bartram Cl (2002) Effect of MRI on clinical outcome of recurrent fistula-in-ano. Lancet. 360(9346):1661-1662

13. Spencer JA, Ward J, Beckingham IJ, Adams C, Ambrose NS (1996) Dynamic contrast-enhanced MR imaging of perianal fistulas. AJR Am J Roentgenol 167(3):735-741

14. Beets-Tan RG, Beets GL, van der Hoop AG, Kessels AG, Vliegen RF, Baeten CG, van Engelshoven JM (2001) Preoperative MR imaging of anal fistulas: does it really help the surgeon? Radiology. 218(1):75-84

15. Horsthuis K, Lavini C, Bipat S, Stokkers PC, Stoker J (2009) Perianal Crohn disease: evaluation of dynamic contrast-enhanced MR imaging as an indicator of disease activity. Radiology. 251(2):380-387

16. Unal O, Koparan HI, Avcu S, Kalender AM, Kisli E (2011) The diagnostic value of diffusion-weighted magnetic resonance imaging in soft tissue abscesses. Eur J Radiol 77(3):490-494
17. Takahara T, Imai Y, Yamashita T, Yasuda S, Nasu S, Van Cauteren M (2004) Diffusion weighted whole body imaging with background body signal suppression (DWIBS): technical improvement using free breathing, STIR and high resolution 3D display. Radiat Med 22(4):275-282

18. Chan JH, Tsui EY, Luk SH, Fung AS, Yuen MK, Szeto ML, Cheung YK, Wong KP (2001) Diffusion-weighted MR imaging of the liver: distinguishing hepatic abscess from cystic or necrotic tumor. Abdom Imaging 26(2):161-165

19. Holzapfel K, Rummeny E, Gaa J (2007) Diffusion-weighted MR imaging of hepatic abscesses: possibility of different apparent diffusion coefficient (ADC)-values in early and mature abscess formation. Abdom Imaging 32(4): 538-539

20. Guo AC, Provenzale JM, Cruz LC Jr, Petrella JR (2001) Cerebral abscesses: investigation using apparent diffusion coefficient maps. Neuroradiology. 43(5):370-374

21. Kim YJ, Chang KH, Song IC, Kim HD, Seong SO, Kim YH, Han MH (1998) Brain abscess and necrotic or cystic brain tumor: discrimination with signal intensity on diffusion-weighted MR imaging. AJR Am J Roentgenol 171(6): $1487-1490$

\section{Publisher's Note}

Springer Nature remains neutral with regard to jurisdictional claims in published maps and institutional affiliations.

\section{Submit your manuscript to a SpringerOpen ${ }^{\circ}$ journal and benefit from:}

- Convenient online submission

- Rigorous peer review

- Open access: articles freely available online

High visibility within the field

- Retaining the copyright to your article

Submit your next manuscript at $\boldsymbol{\triangleright}$ springeropen.com 